\title{
Correlation between hepatopulmonary syndrome and oxygen saturation pulse oximetry in cirrhotic patients
}

\author{
DSara Cardoso Paes Rose 1 \\ (iD) Débora Vilela Cunha ${ }^{1}$ \\ Sandra de Barros Cobra Medeiros ${ }^{3}$ \\ (iD) José Eduardo Trevizoli \\ - Marcos de Vasconcelos Carneiro 2 \\ (D) Wladimir Magalhães de Freitas ${ }^{2}$ \\ (D) Liliana Sampaio Costa Mendes ${ }^{2}$
}

1. Serviço de Gastroenterologia do Instituto Hospital de Base, Faculdade de Medicina, Universidade Católica de Brasília, Brasília, DF, Brasil 2. Serviço de Gastroenterologia, Instituto Hospital de Base do Distrito Federal, Brasília, DF, Brasil 3. Serviço de Cardiologia, Instituto Hospital de Base do Distrito Federal, Brasília, DF, Brasil

\section{SUMMARY}

Hepatopulmonary Syndrome (HPS) is a complication of cirrhosis that worsens the disease's prognosis, pre and post liver transplant. The objective of this study is to analyze the prevalence of HPS in cirrhotic patients at our service and to correlate it with oxygen saturation (SatO2) using a pulse oximeter to evaluate if this is useful as a screening test for HPS. A prospective study was conducted in patients with hepatic cirrhosis conventionally selected from 2014 to 2016. All the patients underwent an echocardiogram with microbubbles and oxygen saturation measurement by pulse oximetry. Those with intrapulmonary shunt were submitted to arterial blood gas analysis. The relationship between oxygen saturation and HPS was assessed by the multivariate model of binary logistic regression. We analyzed 77 patients, and 23.3\% (18 patients) had all criteria for HPS. The relationship between HPS and SatO2 did not show statistical significance, even after the variables were adjusted for sex, age, and smoking. Oxygen saturation alone was not able to detect HPS in the sample of cirrhotic patients. More accurate methods for screening and diagnosis of the syndrome should be used.

KEYWORDS: Hepatopulmonary syndrome. Oximetry. Triage.

\section{INTRODUCTION}

Hepatopulmonary syndrome (HPS) is defined as systemic arterial hypoxemia due to vasodilatations of intrapulmonary capillaries in the presence of liver disease. It is a complication of cirrhosis, with a prevalence of 4-32\% in this population ${ }^{1-3}$. Its pathophysiology is not fully understood and current knowledge on the subject is based mainly on animal experiments and data from patients who are candidates for liver transplantation'generally at a cirrhotic stage. Knowledge about the subject is still only partial. The majority of the information about the etiopathogenesis of HPS has been obtained through experiments on animals. Reported prevalence in patients who are candidates for a liver transplantation (LT.

The pathogenesis of HPS occurs due to the vasodilation of intrapulmonary capillaries. The presence of pulmonary arteriovenous communications (shunts) allows oxygenated blood to mix with non-oxygenated blood, leading to hypoxemia ${ }^{2-4}$ occurring in $10-30 \%$ of patients with cirrhosis. It is due to vasodilation and 
angiogenesis in the pulmonary vascular bed, which leads to ventilation-perfusion mismatching, diffusion limitation to oxygen exchange, and arteriovenous shunting. There is evidence, primarily from animal studies, that vasodilation is mediated by a number of endogenous vasoactive molecules, including endothelin-1 and nitric oxide (NO. The diagnosis of HPS is obtained by detecting the presence of intrapulmonary shunt and hypoxemia in a patient with liver disease ${ }^{1,5,-}$ ${ }^{6}$ generally at a cirrhotic stage. Knowledge about the subject is still only partial. The majority of the information about the etiopathogenesis of HPS has been obtained through experiments on animals. Reported prevalence in patients who are candidates for a liver transplantation (LT. Even though most patients are asymptomatic, HPS decreases the quality of life and worsens the prognosis of these patients, regardless of the degree of liver disease ${ }^{7,8 t h}$ e diagnosis of HPS and oxygen saturation. Thirty cirrhotic patients considered for liver transplantation were enrolled in this study. Pulse oximetry and lung perfusion scintigraphy were conducted in patients while they were in supine and upright body positions. Pathological IPBS was observed in $16 \%$ and $20 \%$ of patients examined in the supine and upright body positions, respectively (mean difference 0.59\%; $\mathrm{P}=0.046$.

The only effective treatment for HPS is liver transplantation ${ }^{9}$. After this procedure, an important improvement of symptoms may occur, and it is possible to completely reverse the condition. However, HPS is also a factor that worsens the prognosis after transplantation, especially in those with $\mathrm{PaO} 2$ less than $50 \mathrm{mmHg}$, when compared to those without the syndrome ${ }^{10,11 t h}$ ree pulmonary complications specific to chronic liver disease have been characterized: hepatopulmonary syndrome (HPS. The presence of HPS with $\mathrm{PaO} 2$ less than $60 \mathrm{mmHg}$ is an independent criterion for priority liver transplantation, despite the value of the MELD score, according to the current regulation of liver transplantation in Brasil ${ }^{12}$.

Therefore, an effective method for screening HPS is highly necessary ${ }^{13}$. There is no well-established protocol for verifying the presence of shunt and HPS in pre-transplant patients. Several transplant centers in the country and in the world do not perform an exam for detecting the presence of intrapulmonary shunt as a routine before transplantation. Many centers use oxygen saturation by pulse oximetry (SatO2) for SHP screening ${ }^{1,14}$ generally at a cirrhotic stage. Knowledge about the subject is still only partial. The majority of the information about the etiopathogenesis of HPS has been obtained through experiments on animals. Reported prevalence in patients who are candidates for a liver transplantation (LT).

The objective of this study is to analyze the prevalence of HPS in cirrhotic patients in our service and correlate it with oxygen saturation (SatO2) by pulse oximeter to verify if this could be a reliable screening test for the diagnosis of HPS.

\section{METHODS}

This was a prospective study that included patients with liver cirrhosis who attended the hepatology outpatient clinic at the Hospital de Base do Distrito Federal from 2014 to 2016. The diagnosis of cirrhosis in these patients was previously made through a histopathological study or by a combination of clinical, radiological and laboratory findings. Patients with hepatocarcinoma, active infectious process, hospitalization in the previous 30 days, and those who underwent liver transplantation were excluded from the series.

Oxygen saturation by pulse oximetry (SatO2) was measured for all patients during their participation in the study. The SatO2 value of $96 \%$ was considered as the cutoff point for analysis. An echocardiogram with microbubbles was also requested for all patients to verify the presence or absence of intrapulmonary shunt. All those who had a positive intrapulmonary shunt were subjected to arterial blood gas analysis to measure the alveolar-arterial gradient and $\mathrm{PaO} 2$. All patients underwent chest X-ray and spirometry, and those who presented abnormalities in these exams were excluded.

The criteria for hepatopulmonary syndrome in our study were the presence of liver disease with positive intrapulmonary shunt and hypoxemia, $\mathrm{PaO} 2<80$ $\mathrm{mmHg}$, and/or alveolar-arterial gradient greater than $15 \mathrm{mmHg}$ or greater than $20 \mathrm{mmHg}$, in patients older than 64 years ${ }^{15}$. Patients with HPS were classified as mild ( $\mathrm{PaO} 2>80 \mathrm{mmHg})$, moderate ( $\mathrm{PaO} 2$ between 60 and $80 \mathrm{mmHg}$ ), and severe ( $\mathrm{PaO} 2 \leq 60 \mathrm{mmHg})$.

Continuous variables with normal and non-parametric distribution were evaluated by mean, standard deviation, median, and interquartile range. Nominal percentages and ordinal variables were analyzed by median and interquartile range. The chi-square test was used to compare proportions, when necessary. For the comparison of continuous 
or orderly measurements between two groups, the Mann-Whitney test was applied. The relationship between SatO2 and HPS was evaluated by the multivariate model of binary logistic regression. The individuals were characterized in the dependent variable "presence" or "absence" of HPS first in an unadjusted model and later adjusted for the variables of sex, age and smoking.

All patients enrolled in the study consented to their participation through the Informed Consent Form. This study was approved by the Brazilian Ethics Committee (Pesquisa/Fepecs/Plataforma Brasil - CAAE: 47514315.7.0000.5553V2).

\section{RESULTS}

In the beginning, the study sample included 102 patients. There was a loss of 25 patients $(24.5 \%$ of total). The main reasons for this were: refusal to perform the requested tests and giving up on continuing the study (13 patients, 12, 7\%). Four patients (3.9\%) died in the period. One patient (0.9\%) was excluded after liver transplantation. In the end, 77 patients $(75.4 \%)$ were evaluated.

The characteristics of the sample can be seen in Table 1. Liver cirrhosis due to $\mathrm{C}$ virus was the most prevalent (33.7\%, 26 patients), followed by alcoholic cirrhosis (24.6\%, 19 patients). Cirrhosis classified as Child-Pugh A was the most prevalent (68\%, 52 patients). Patients with Child-Pugh B cirrhosis and
TABLE 1.

\begin{tabular}{l|l|}
\hline Gender: Male (\%. n) & $51.9 \% .41$ \\
\hline Age. years & $54.6+/-10.6$ \\
\hline BMI. kg/m² & $26+/-4.7$ \\
\hline SatO2 (\%) & $97 \%(95-97)$ \\
\hline Current smoking (\%. n) & $13.9 \% .11$ \\
\hline Previous smoking (\%.n) & $26.6 \% .26 .5$ \\
\hline Current alcoholism (\%.n) & $6.3 \% .5$ \\
\hline Previous alcoholism(\%.n) & $26.6 \% .21$ \\
\hline
\end{tabular}

Child-Pugh C cirrhosis were 26\% (20 patients) and 6\% (5 patients), respectively.

The patients that had positive intrapulmonary shunt were $77,29.8 \%$ (23 patients), however, only 23.3\% (18 patients) had all the criteria for HPS. Among the patients with HPS 55.5\% (10 patients) had the syndrome in its mild form, 38.8\% (7 patients) had a moderate form and $5.5 \%$ (1 patient) had a severe form of HPS (Figure 1).

There were no patients with mild HPS that had SatO2 less than 96\%. Among those with the moderate syndrome, $42.8 \%$ (3 patients) had a SatO2 less than $96 \%$, and $57.2 \%$ (4 patients) had a SatO2 greater than or equal to $96 \%$. Only one patient had severe HPS and a SatO2 equal to $98 \%$. In a multivariate model of logistic regression, the determination of SatO2 alone was not able to predict individuals with HPS even after adjusting for age, sex, and current and previous smoking. The relationship between HPS and SatO2, using the binary logistic regression model, showed an unadjusted exponent B value of 1.12 (IC 0.77 - 1.6, p =

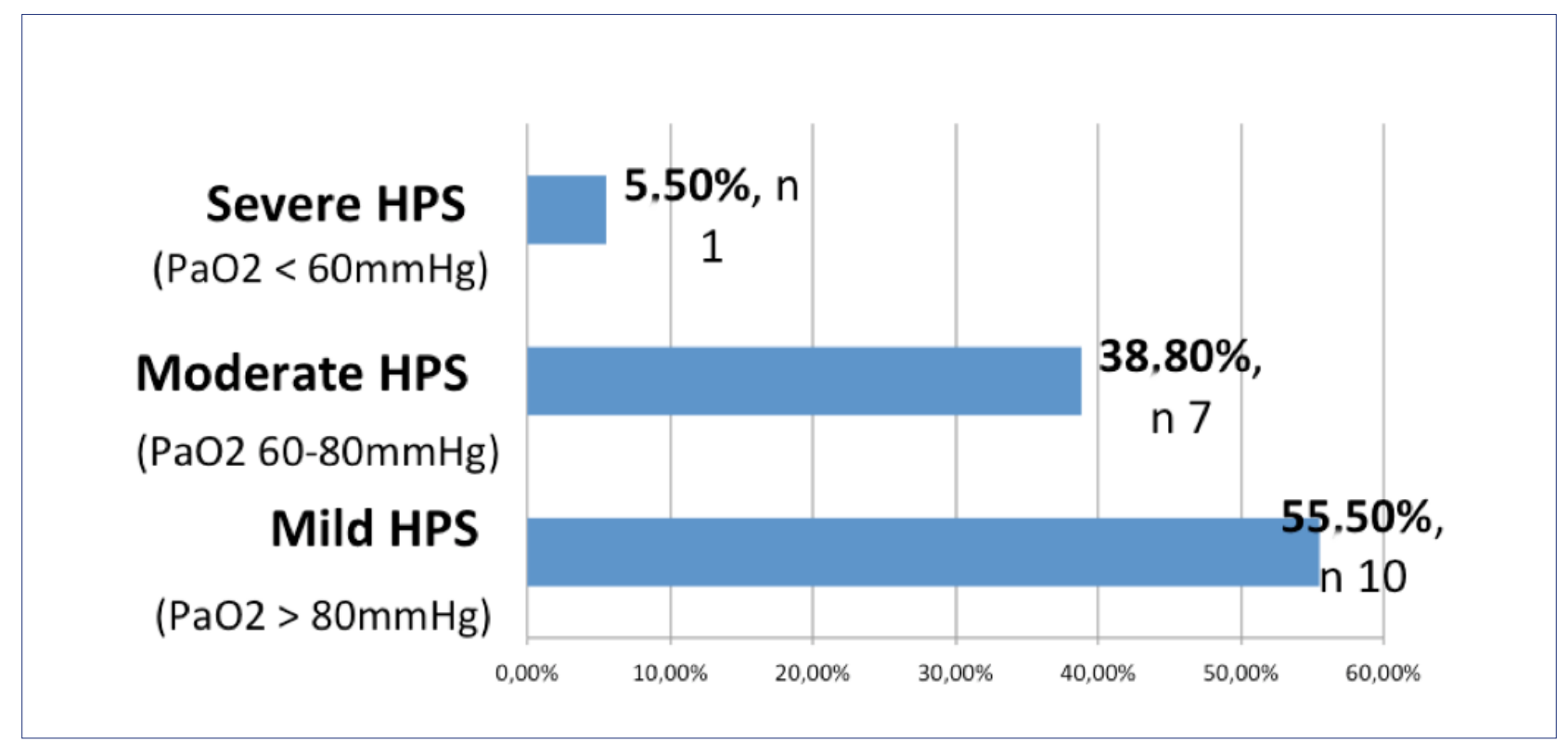




\section{TABLE 2.}

\begin{tabular}{l|l|l|l|l} 
Variable & $\begin{array}{l}\text { Ex- } \\
\text { p(B) }\end{array}$ & P & $\begin{array}{l}\text { C.I of 95\% for } \\
\text { EXP (B) }\end{array}$ \\
\hline \multicolumn{5}{|c|}{$\begin{array}{c}\text { Inferior } \\
\text { Superior }\end{array}$} \\
\hline SatO2 & 1.127 & 0.526 & 0 & 1.628 \\
\hline SatO2 + Age & 0.965 & 0.235 & 0.910 & 1.023 \\
\hline SatO2 + Age + Sex & 1.355 & 0.618 & 0.411 & 4.469 \\
\hline SatO2 + Age + Sex + Smoking & 0.835 & 0.836 & 0.152 & 4.577 \\
\hline
\end{tabular}

0.52). After the variables were adjusted for sex, age, and current and past smoking, the adjusted B exponent value was 0.83 (IC $0.15-4.5, p=0.83$ ). In both cases, there was no statistical significance (Table 2).

\section{DISCUSSION}

The evaluation of oxygen saturation by pulse oximetry is a non-invasive, low-cost method, and, for this reason, it has been used as screening for HPS. The cutoff values for HPS have not yet been well established. The most used value was proposed by Arguedas et al, in 2007, after a study with 127 patients referred for liver transplant evaluation. Of these, 40 patients had HPS. The oxygen saturation value by pulse oximetry below $96 \%$ obtained sensitivity and specificity, respectively, of $100 \%$ and $88 \%$ in detecting patients with $\mathrm{PaO} 2$ below $60 \mathrm{mmHg}^{16}$.

Kochar et al. ${ }^{17}$ proposed that patients with HPS evolve with a significant decrease in SatO2, when compared with those without HPS. He conducted a 20-month prospective cohort that compared 22 patients with HPS with 32 patients without the syndrome.

However, in our study, the relationship between oxygen saturation by pulse oximetry and HPS through logistic regression obtained a non-significant p-value and an unreliable confidence interval (CI). This indicates that SatO2, as an isolated method, was not able to distinguish patients with HPS from those without the syndrome.

The prevalence of HPS was $23.3 \%$ in our study, similar to what is found in the literature ${ }^{1,3}$ generally at a cirrhotic stage. Knowledge about the subject is still only partial. The majority of the information about the etiopathogenesis of HPS has been obtained through experiments on animals. Reported prevalence in patients who are candidates for a liver transplantation (LT. However, there was a higher prevalence of mild to moderate HPS (94.3\%), when compared to the values found in the literature (77-88\%) ${ }^{1}$ generally at a cirrhotic stage. Knowledge about the subject is still only partial. The majority of the information about the etiopathogenesis of HPS has been obtained through experiments on animals. Reported prevalence in patients who are candidates for a liver transplantation (LT. The results in our sample may be a reason why SatO2 has not been an effective method for screening for HPS, as it can detect more severe cases of the syndrome ${ }^{16}$. However, lower levels of SatO2 was not observed in moderate to severe cases of HPS in our sample, as was reported by Kochar et al. ${ }^{17}$. Most patients with moderate HPS presented SatO2 greater than or equal to $96 \%(57.2 \%)$, and one patient with severe SHP had normal SatO2 (98\%).

Hoerning et al. ${ }^{18}$ conducted a study with 57 children aged from 1 to 17 years (mean of $4.6+/-5.0$ years) with liver cirrhosis to verify the usefulness of pulse oximetry in patients with HPS. Despite being a study performed in children, pulse oximetry was also not a useful method for the early diagnosis of HPS, but only for more severe cases of HPS. A total of 18 patients with intrapulmonary shunt had SatO2 above $98 \%$. Of these, 2 patients (11\%) had moderate HPS, with $\mathrm{P}$ (A-a) O2> 15mmHg and $\mathrm{PaO} 2<70 \mathrm{mmHg}$, despite normal saturation, and died before obtaining a liver transplant ${ }^{18 \text { the }}$ importance of pulse oximetry in diagnosing HPS, and the longitudinal course after liver transplantation in children with cirrhosis referred for liver transplantation. Study design Fifty-six patients aged 1-17 years (mean age, $4.6 \pm 5.0$ years.

Pulse oximetry can also have other limitations when used as a screening test for all cirrhotic patients. It may not be precise enough when compared to arterial blood gases $(\mathrm{PaO} 2)$ and tends to overestimate the values of arterial oxygenation, especially in smoking individuals ${ }^{1,19}$ generally at a cirrhotic stage. Knowledge about the subject is still only partial. The majority of the information about the etiopathogenesis of HPS has been obtained through experiments on animals. Reported prevalence in patients who are candidates for a liver transplantation (LT. This should be considered, particularly when the number of smoking patients in the sample is important. In our sample, $13.9 \%$ (11 patients) were smokers during the study period and $26.6 \%$ were former smokers.

The limitations of our study were the reduced number of patients, because of the losses due to non-follow-up. Prospective studies that assess the relationship between SatO2 and HPS with a higher number of patients are still quite scarce. 
Thus, oxygen saturation was not a good screening test for HPS in cirrhotic patients in our study. The higher prevalence of patients with mild HPS in our sample may have had a considerable impact on these results. Performing an echocardiogram with microbubbles in all cirrhotic patients, especially those in waiting for a transplant can be a useful method to detect patients with HPS. The earlier detection of this syndrome can lead to a better evaluation of patients and to further knowledge of its natural history. It can also lead to indications of liver transplant at an earlier and more opportune moment, before other complications of cirrhosis may limit the results of this operation.

\section{CONCLUSION}

Oxygen saturation measured by pulse oximetry, as an isolated method, was not able to screen HPS among a sample of cirrhotic patients. Lower levels of saturation may indicate the presence of HPS; however, the absence of this finding does not exclude the presence of the syndrome. Thus, the use of more accurate tests, such as the echocardiogram with microbubbles associated with arterial blood gases, is a more accurate alternative for screening and diagnosing HPS, especially in patients in the liver transplant queue.

\section{Conflicts of interest}

There were no conflicts of interest between the authors of this study.

\section{Acknowledgments \\ Biocardios}

\section{Author's Contribution}

SCPR contributed with project management, data curation, formal analysis, investigation, methodology, writing of the original draft, review and editing. DVC contributed with data curation and formal analysis. SBC contributed with data curation and investigation. JET contributed with conceptualization, project management, and resources. MVC contributed with conceptualization, methodology, resources, review and editing. WMF contributed with formal analysis, software, and validation. LSCM lead the project management and supervision and contributed with the conceptualization, investigation, methodology, resources, validation, review and editing.

\section{RESUMO}

A Síndrome Hepatopulmonar (SHP) é uma complicação da cirrose que piora o prognóstico da doença pré e pós-transplante hepático. O objetivo do trabalho é analisar a prevalência de SHP em pacientes cirróticos de nosso serviço e correlacioná-la com a saturação de oxigênio (SatO2) pelo oxímetro de pulso, e avaliar se este seria útil como um exame de triagem no diagnóstico de SHP. Foi realizado um estudo prospectivo em pacientes portadores de cirrose hepática no período de 2014 a 2016. Todos os pacientes foram submetidos a um ecocardiogama com microbolhas e a saturação de oxigênio pela oximetria de pulso. Aqueles com shunt intrapulmonar foram submetidos a gasometria arterial. A relação entre a saturação de oxigênio e SHP foi avaliada pelo modelo multivariado de regressão logística binário. Foram analisados 77 pacientes, destes 23,3\% (18 pacientes) apresentaram todos os critérios para SHP. A relação entre a SHP com a SatO2 não obteve significância estatística, mesmo após as variáveis terem sido ajustadas pelo sexo, idade e tabagismo atual ou passado. A saturação de oxigênio, de forma isolada, não foi capaz de distinguir a SHP na amostra de pacientes cirróticos em nosso estudo. Deve-se utilizar métodos mais acurados para a triagem e diagnóstico dessa síndrome.

PALAVRAS-CHAVE: Síndrome hepatopulmonar. Oximetria. Triagem.

\section{REFERENCES}

1. Grilo-Bensusan I, Pascasio-Acevedo JM. Hepatopulmonary syndrome: what we know and what we would like to know. World J Gastroenterol. 2016;22(25):5728-41.

2. Grace JA, Angus PW. Hepatopulmonary syndrome: update on recent advances in pathophysiology, investigation, and treatment. | Gastroenterol Hepatol. 2013;28(2):213-9.

3. Rodríguez-Roisin R, Krowka MJ. Hepatopulmonary syndrome: a liver-induced lung vascular disorder. N Engl J Med. 2008;358(22):2378-87.

4. Schenk P, Fuhrmann V, Madl C, Funk G, Lehr S, Kandel O, et al. Hepatopulmonary syndrome: prevalence and predictive value of various cut offs for arterial oxygenation and their clinical consequences. Gut. 2002;51(6):853-9.
5. Lima BLG, França AVC, Pazin-Filho A, Araújo WM, Martinez |AB, Maciel $B C$, et al. Frequency, clinical characteristics, and respiratory parameters of hepatopulmonary syndrome. Mayo Clin Proc. 2004;79(1):42-8.

6. Franca A, Lima B, Pazin Filho A, Araújo W, Martinez J, Maciel B, et al. Evolution of intrapulmonary vascular dilitations in cirrhosis. Hepatology. 2004;39(5):1454

7. Boryczka G, Hartleb M, Rudzki K, Janik MA. Influence of an upright body position on the size of intrapulmonary blood shunts in patients with advanced liver cirrhosis. J Physiol Pharmacol. 2015;66(6):855-61.

8. Voiosu AM, Voiosu TA, Smarandache B, Rădoi A, Mateescu RB, Băicuş $C R$, et al. The impact of hypoxaemia on the outcome in liver cirrhosis. | 
Gastrointest Liver Dis. 2016;25(4):481-7.

9. Suceveanu Al, Mazilu L, Tomescu D, Ciufu N, Parepa IR, Suceveanu AP. Screening of hepatopulmonary syndrome (HPS) with CEUS and pulse-oximetry in liver cirrhosis patients eligible for liver transplant. Chirurgia (Bucur). 2013;108(5):684-8.

10. Machicao VI, Balakrishnan M, Fallon MB. Pulmonary complications in chronic liver disease. Hepatology. 2014;59(4):1627-37.

11. Nacif LS, Andraus W, Pinheiro RS, Ducatti L, Haddad LBP, D'Albuquerque LC. Síndrome hepatopulmonar. ABCD Arq Bras Cir Dig. 2014;27(2):145-7.

12. Brasil. Ministério da Saúde. Portaria n².600, de 21 de Outubro de 2009 Aprova o regulamento técnico do sistema nacional de transplantes. [cited 2020 Mar 12]. Available from: http://www.brasilsus.com.br/legislacoes/ $\mathrm{gm} / 101249-2600 . \mathrm{htm}$

13. Roberts DN, Arguedas MR, Fallon MB. Cost-effectiveness of screening for hepatopulmonary syndrome in liver transplant candidates. Liver Transpl.
2007;13(2):206-14.

14. Lv Y, Fan D. Hepatopulmonary syndrome. Dig Dis Sci. 2015;60(7):1914-23.

15. Sriram PB, Sindhuja R, Natarajan M, Arul Rajamurugan PS, Palanikumar B. A case of hepatopulmonary syndrome. J Clin Diagn Res. 2016;10(3):OD17-9.

16. Arguedas MR, Singh H, Faulk DK, Fallon MB. Utility of pulse oximetry screening for hepatopulmonary syndrome. Clin Gastroenterol Hepatol. 2007;5(6):749-54

17. Kochar R, Tanikella R, Fallon MB. Serial pulse oximetry in hepatopulmonary syndrome. Dig Dis Sci. 2011;56(6):1862-8.

18. Hoerning A, Raub S, Neudorf U, Müntjes C, Kathemann S, Lainka E, et al. Pulse oximetry is insufficient for timely diagnosis of hepatopulmonary syndrome in children with liver cirrhosis. J Pediatr. 2014;164(3):546-52.

19. Krowka MJ. Hepatopulmonary syndrome: monitoring at your fingertip. Dig Dis Sci. 2011;56(6):1599-600. 